\title{
Shrinking projection algorithms for equilibrium problems with a bifunction defined on the dual space of a Banach space
}

\author{
Jia-wei Chen ${ }^{1}$, Yeol Je Cho ${ }^{2^{*}}$ and Zhongping Wan ${ }^{1}$
}

\footnotetext{
* Correspondence: yjcho@gnu.ac.kr ${ }^{2}$ Department of Mathematics Education and the RINS, Gyeongsang National University, Chinju 660-701, Republic of Korea Full list of author information is available at the end of the article
}

\begin{abstract}
Shrinking projection algorithms for finding a solution of an equilibrium problem with a bifunction defined on the dual space of a Banach space, in this paper, are introduced and studied. Under some suitable assumptions, strong and weak convergence results of the shrinking projection algorithms are established, respectively. Finally, we give an example to illustrate the algorithms proposed in this paper.

2000 Mathematics Subject Classification: 47H09; 65J15; 90C99.

Keywords: equilibrium problem, strong and weak convergence, shrinking projection algorithm, sunny generalized nonexpansive retraction, fixed point
\end{abstract}

\section{Introduction}

Let $\Omega$ be a nonempty closed subset of a real Hilbert space $H$. Let $g$ be a bifunction from $\Omega \times \Omega$ to $R$, where $R$ is the set of real numbers. The equilibrium problem for $g$ is as follows: Find $\bar{x} \in \Omega$ such that

$$
g(\bar{x}, y) \geq 0, \quad \forall y \in \Omega .
$$

Many problems in structural analysis, optimization, management sciences, economics, variational inequalities and complementary problems coincide to find a solution of the equilibrium problem. Various methods have been proposed to solve some kinds of equilibrium problems in Hilbert and Banach spaces (see [1-8]).

In [9], Takahashi and Zembayashi proved strong and weak convergence theorems for finding a common element of the set of solutions of an equilibrium problem and the set of fixed points of a relatively nonexpansive mapping in Banach spaces. Ibaraki and Takahashi [10] introduced a new resolvent of a maximal monotone operator in Banach spaces and the concept of the generalized nonexpansive mapping in Banach spaces. Honda et al. [11], Kohsaka and Takahashi [12] also studied some properties for the generalized nonexpansive retractions in Banach spaces. Takahashi et al. [13] proved a strong convergence theorem for nonexpansive mapping by hybrid method. In 2009, Ceng et al. [2] proved strong and weak convergence theorems for equilibrium problems and dealt maximal monotone operators by hybrid proximal-point methods. Motivated by Ibaraki

(c) 2011 Chen et al; licensee Springer. This is an Open Access article distributed under the terms of the Creative Commons Attribution License (http://creativecommons.org/licenses/by/2.0), which permits unrestricted use, distribution, and reproduction in any medium, provided the original work is properly cited. 
and Takahashi [10] and Takahashi et al. [13], Takahashi and Zembayashi [14] considered the following equilibrium problem:

Let $E$ be a smooth Banach space with dual space $E^{*}$ and $C$ be a nonempty closed subset of $E$ such that $J(C)$ is a closed and convex subset of $E^{*}$, where $J$ is the normalized duality mapping from $E$ onto $E^{*}$. Let $f: J(C) \times J(C) \rightarrow R$ be a mapping. Consider the equilibrium problem as follows: Find $\bar{x} \in C$ such that

$$
f(J(\bar{x}), J(y)) \geq 0, \quad \forall y \in C .
$$

Then they proved a strong convergence theorem for finding a solution of the equilibrium problem (1.1) in Banach spaces. Forward, we denote the set of solutions of the problem (1.1) by $E P(f)$ :

Inspired and motivated by Ceng et al. [2], Takahashi and Zembayashi [14], Takahashi and Zembayashi [9], the main aim of this paper is to introduce and investigate a new iterative method for finding a solution of the equilibrium problem (1.1). Under some appropriate assumptions, strong and weak convergence results of the iterative algorithms are established, respectively. Furthermore, we also give an example to illustrate the algorithms proposed in this paper.

\section{Preliminaries}

Throughout this paper, we denote the sets of nonnegative integers and real numbers by $Z_{+}$and $R$, respectively.

Let $E$ be a real Banach space with the dual space $E^{*}$. The norm and the dual pair between $E$ and $E^{*}$ are denoted by $\|\cdot\|$ and $\langle\cdot, \cdot\rangle$, respectively. The weak convergence and strong convergence are denoted by $\rightarrow$ and $\rightarrow$, respectively. Let $C$ be a nonempty closed subset of $E$. We denote the normalized duality mapping from $E$ to $E^{*}$ by $J$ defined by

$$
J(x)=\left\{j(x) \in E^{*}:\langle j(x), x\rangle=\|j(x)\|\|x\|=\|j(x)\|^{2}=\|x\|^{2}\right\}, \quad \forall x \in E .
$$

$J$ is said to be weakly sequentially continuous if the strong convergence of a sequence $\left\{x_{n}\right\}$ to $x$ in $E$ implies the weak* convergence of $\left\{J\left(x_{n}\right)\right\}$ to $J(x)$ in $E^{*}$.

Many properties of the normalized duality mapping $J$ can be found in [15-17] and, now, we list the following properties:

$\left(\mathrm{p}^{1}\right) J(x)$ is nonempty for any $x \in E$;

$\left(\mathrm{p}^{2}\right) J$ is a monotone and bounded operator in Banach spaces;

$\left(\mathrm{p}^{3}\right) J$ is a strictly monotone operator in strictly convex Banach spaces;

$\left(\mathrm{p}^{4}\right) J$ is the identity operator in Hilbert spaces;

$\left(\mathrm{p}^{5}\right)$ If $E$ is a reflexive, smooth and strictly convex Banach space and $J^{*}: E^{*} \rightarrow 2^{E}$ is the normalized duality mapping on $E^{*}$, then $J^{1}=J^{*} ; J J^{*}=I_{E}^{*}$ and $J^{* *} J=I_{E}$; where $I_{E}^{* *}$ and $I E^{* * a r e}$ the identity mappings on $E$ and $E^{*}$, respectively.

(p6) If $E$ is a strictly convex Banach space, then $J$ is one to one, that is,

$$
x \neq y \quad \Rightarrow \quad J(x) \cap J(y)=\emptyset ;
$$

$\left(\mathrm{p}^{7}\right)$ If $E$ is smooth, then $J$ is single-valued;

$\left(\mathrm{p}^{8}\right) E$ is a uniformly convex Banach space if and only if $E^{*}$ is uniformly smooth;

$\left(\mathrm{p}^{9}\right)$ If $E$ is uniformly convex and uniformly smooth Banach space, then $J$ is uniformly norm-to-norm continuous on bounded subsets of $E$ and $J^{1}=J^{*}$ is also uniformly norm-to-norm continuous on bounded subsets of $E^{*}$ : 
Let $E$ be a smooth Banach space. Let a function $\varphi: E \times E \rightarrow R$ be defined as follows:

$$
\phi(x, y)=\|x\|^{2}-2\langle x, J(y)\rangle+\|y\|^{2}, \quad \forall x, y \in E .
$$

Then we have

$$
\phi(x, y)=\phi(x, z)+\phi(z, y)+2\langle x-z, J(z)-J(y)\rangle, \quad \forall x, y, z \in E .
$$

Remark 2.1. (see $[17,18])$ The following statements hold:

(1) If $E$ is a reflexive, strictly convex and smooth Banach space, then, for all $x, y \in E$, $\varphi(x ; y)=0$ if and only if $x=y$;

(2) If $E$ is a Hilbert space, then $\varphi(x, y)=\|x-y\|^{2}$ for all $x ; y \in E$;

(3) For all $x, y \in E,(\|x\|-\|y\|)^{2} \leq \varphi(x, y) \leq(\|x\|+\|y\|)^{2}$.

For solving the equilibrium problem (1.1), we assume that $f: J(C) \times J(C) \rightarrow \mathrm{R}$ satisfies the following conditions $(A 1)-(A 4)[9]$ :

(A1) $f\left(x^{*}, x^{*}\right)=0$ for all $x^{*} \in J(C)$;

(A2) $f$ is monotone, that is, $f\left(x^{*} ; y^{*}\right)+f\left(y^{*}, x^{*}\right) \leq 0$ for all $x^{*}, y^{*} \in J(C)$;

(A3) $f$ is upper hemicontinuous, that is, for all $x^{*}, y^{*}, z^{*} \in J(C)$,

$$
\limsup _{t \rightarrow 0^{+}} f\left(x^{*}+t\left(z^{*}-x^{*}\right), y^{*}\right) \leq f\left(x^{*}, y^{*}\right) ;
$$

(A4) For all $x^{*} \in J(C), f\left(x^{*}, \cdot\right)$ is convex and lower semicontinuous.

In the sequel, we recall some concepts and results.

Definition 2.1. (see [11]) Let $C$ be a nonempty closed subset of a smooth Banach space $E$. A mapping $T: C \rightarrow C$ is said to be generalized nonexpansive if $F(T)$ is nonempty and

$$
\phi(T x, p) \leq \phi(x, p), \quad \forall x \in C, p \in F(T),
$$

where $F(T)$ denotes the set of fixed points of $T$, that is, $F(T)=\{x \in \mathrm{C}: T x=x\}$.

Definition 2.2. (see [11]) Let $C$ be a nonempty closed subset of $E$. A mapping $R$ : $E \rightarrow C$ is called:

(1) a retraction if $R^{2}=R$;

(2) sunny if $R(R x+t(x-R x))=R x$ for all $x \in E$ and $t>0$.

Definition 2.3. (see [11]) A nonempty closed subset $C$ of a smooth Banach space $E$ is called a sunny generalized nonexpansive retract of $E$ if there exists a sunny generalized nonexpansive retraction $R$ from $E$ onto $C$.

Lemma 2.1. (see [19]) Let $E$ be a uniformly convex and smooth Banach space, and let $\left\{x_{n}\right\}$ and $\left\{y_{n}\right\}$ be two sequences of $E$. If $\varphi\left(x_{n}, y_{n}\right) \rightarrow 0$ and either $\left\{x_{n}\right\}$ or $\left\{y_{n}\right\}$ is bounded, then $x_{\mathrm{n}}-y_{n} \rightarrow 0$.

Lemma 2.2. (see [18]) Let $E$ be a uniformly convex Banach space. Then, for any $r>0$; there exists a strictly increasing, continuous and convex function $h:[0,2 r] \rightarrow R$ such that $h(0)=0$ and

$$
\|t x+(1-t) y\|^{2} \leq t\|x\|^{2}+(1-t)\|y\|^{2}-t(1-t) h(\|x-y\|), \quad \forall x, y \in B_{r}, t \in[0,1],
$$

where $B_{r}=\{\mathrm{z} \in E:\|z\| \leq r\}$.

Lemma 2.3. (see [1]) Let $C$ be a nonempty closed subset of a smooth, strictly convex and reflexive Banach space $E$ such that $J(C)$ is closed and convex. Assume that a mapping $f: J(C) \times J(C) \rightarrow R$ satisfies the conditions (A1)-(A4). Then, for any $r>0$ and $x \in$ 
$E$, there exists $z \in C$ such that

$$
f(J(z), J(y))+\frac{1}{r}\langle z-x, J(y)-J(z)\rangle \geq 0, \quad \forall y \in C .
$$

Lemma 2.4. (see [14]) Let $C$ be a nonempty closed subset of a uniformly smooth, strictly convex and reflexive Banach space $E$ such that $J(C)$ is closed and convex. Assume that a mapping $f: J(C) \times J(C) \rightarrow R$ satisfies the conditions (A1)-(A4). For any $r$ $>0$ and $x \in E$, define a mapping $T_{r}: E \rightarrow C$ by

$$
T_{r}(x)=\left\{z \in C: f(J(z), J(y))+\frac{1}{r}\langle z-x, J(y)-J(z)\rangle \geq 0, \forall y \in C\right\}, \quad \forall x \in E .
$$

Then the following statements hold:

(1) $T_{r}$ is single-valued;

(2) For all $x, y \in E$,

$$
\left\langle T_{r}(x)-T_{r}(y), J\left(T_{r}(x)\right)-J\left(T_{r}(y)\right)\right\rangle \leq\left\langle x-y_{,} J\left(T_{r}(x)\right)-J\left(T_{r}(y)\right)\right\rangle ;
$$

(3) $F\left(T_{r}\right)=E P(f)$ and $J(E P(f))$ is closed and convex;

(4) $\varphi\left(x, T_{r}(x)\right)+\varphi\left(T_{r}(x), p\right) \leq \varphi(x, p)$ for all $x \in E$ and $p \in F\left(T_{r}\right)$.

Lemma 2.5. (see [9]) Let $C$ be a nonempty closed subset of a smooth, strictly convex and reflexive Banach space $E$, and let $R$ be a retraction of $E$ onto $C$. Then the following statements are equivalent:

(1) $R$ is sunny generalized nonexpansive;

(2) $\langle x-R x, J(y)-J(R x)\rangle \leq 0$ for all $(x, y) \in E \times C$.

Lemma 2.6. (see [20]) Let $C$ be a nonempty closed sunny generalized nonexpansive retract of a smooth and strictly convex Banach space $E$. Then the sunny generalized nonexpansive retraction from $E$ onto $C$ is uniquely determined.

Lemma 2.7. (see [10]) Let $C$ be a nonempty closed subset of a smooth and strictly convex Banach space $E$ such that there exists a sunny generalized nonexpansive retraction $R$ from $E$ onto $C$. Then, for any $x \in E$ and $z \in C$, the following statements hold:

(1) $z=R x$ if and only if $\langle x-z, J(y) \leq J(z)\rangle \leq 0$ for all $y \in C$;

(2) $\varphi(x, R x)+\varphi(R x, z) \leq \varphi(x, z)$.

Lemma 2.8. (see [12]) Let $C$ be a nonempty closed subset of a smooth, strictly convex and reflexive Banach space $E$. Then the following statements are equivalent:

(1) $C$ is a sunny generalized nonexpansive retract of $E$;

(2) $J(C)$ is closed and convex.

Remark 2.2. If $E$ is a Hilbert space, then, from Lemmas 2.6 and 2.8, a sunny generalized nonexpansive retraction from $E$ onto $C$ reduces to a metric projection operator $P$ from $E$ onto $C$.

Lemma 2.9. (see [12]) Let $C$ be a nonempty closed sunny generalized nonexpansive retract subset of a smooth, strictly convex and reflexive Banach space $E$. Let $R$ be the sunny generalized nonexpansive retraction from $E$ onto $C$. Then, for any $x \in E$ and $z \in C$,

$$
z=R x \quad \Leftrightarrow \quad \phi(x, z)=\min _{y \in C} \phi(x, y) .
$$

Lemma 2.10. (see [21]) Let $\left\{a_{n}\right\}$ and $\left\{b_{n}\right\}$ be two sequences of nonnegative real numbers satisfying the inequality 


$$
a_{n+1} \leq a_{n}+b_{n}, \quad \forall n \in Z_{+} .
$$

If $\sum_{n=0}^{\infty} b_{n}<\infty$, then $\lim _{n \rightarrow \infty} a_{n}$ exists.

\section{Main results}

In this section, we propose iterative algorithms for finding a solution of the equilibrium problem (1.1) and prove the strong and weak convergence for the algorithms in a Banach space under some suitable conditions.

Theorem 3.1. Let $C$ be a nonempty closed subset of a uniformly convex and uniformly smooth Banach space $E$ such that $J(C)$ is closed and convex. Assume that a mapping $f: J(C) \times J(C) \rightarrow R$ satisfies the conditions (A1)-(A4). Define a sequence $\left\{x_{n}\right\}$ in $C$ by the following algorithm:

$$
\left\{\begin{array}{l}
x_{0} \in C, \\
u_{n} \in C \text { such that } f\left(J\left(u_{n}\right), J(y)\right)+\frac{1}{r_{n}}\left\langle u_{n}-x_{n}, J(y)-J\left(u_{n}\right)\right\rangle \geq 0, \quad \forall y \in C, \\
x_{n+1}=\alpha_{n} x_{0}+\left(1-\alpha_{n}\right)\left(\beta_{n} x_{n}+\left(1-\beta_{n}\right) u_{n}\right), \quad \forall n \in Z_{+}
\end{array}\right.
$$

where $\left\{\alpha_{n}\right\},\left\{\beta_{n}\right\} \subset[0,1]$ such that

$$
\sum_{n=0}^{\infty} \alpha_{n}<\infty, \quad \liminf _{n \rightarrow \infty} \beta_{n}\left(1-\beta_{n}\right)>0, \quad \liminf _{n \rightarrow \infty} r_{n}>0 .
$$

Then the sequence $\left\{R_{E P(f)} x_{n}\right\}$ converges strongly to a point $\omega \in E P(f)$, where $R_{E P(f)}$ is the sunny generalized nonexpansive retraction from $E$ onto $E P(f)$.

Proof. For the sake of simplicity, let $u_{n}=T_{r_{n}} x_{n}$ and $y_{n}=\beta_{n} x_{n}+\left(1-\beta_{n}\right) u_{n}$. Then $x_{n+1}$ $=\alpha_{n} x_{0}+\left(1-\alpha_{n}\right) y_{n}$. From Lemma 2.4 , it follows that $E P(f)$ is a nonempty closed and convex subset of $E$.

First, we claim that $\left\{x_{n}\right\}$ is bounded. Indeed, let $\omega \in E P(f)$. Since

$$
\begin{aligned}
\phi\left(y_{n}, \omega\right)= & \left\|\beta_{n} x_{n}+\left(1-\beta_{n}\right) u_{n}\right\|^{2}-2\left\langle\beta_{n} x_{n}+\left(1-\beta_{n}\right) u_{n} J(\omega)\right\rangle+\|\omega\|^{2} \\
& \leq \beta_{n}\left\|x_{n}\right\|^{2}+\left(1-\beta_{n}\right)\left\|u_{n}\right\|^{2}-2 \beta_{n}\left\langle x_{n}, J(\omega)\right\rangle-2\left(1-\beta_{n}\right)\left\langle u_{n} J(\omega)\right\rangle+\|\omega\|^{2} \\
= & \beta_{n} \phi\left(x_{n}, \omega\right)+\left(1-\beta_{n}\right) \phi\left(u_{n}, \omega\right) \\
= & \beta_{n} \phi\left(x_{n}, \omega\right)+\left(1-\beta_{n}\right) \phi\left(T_{r_{n}} x_{n}, \omega\right) \\
& \leq \phi\left(x_{n}, \omega\right),
\end{aligned}
$$

we have

$$
\begin{aligned}
\phi\left(x_{n+1}, \omega\right) & \leq \alpha_{n} \phi\left(x_{0}, \omega\right)+\left(1-\alpha_{n}\right) \phi\left(y_{n}, \omega\right) \\
& \leq \alpha_{n} \phi\left(x_{0}, \omega\right)+\left(1-\alpha_{n}\right) \phi\left(x_{n}, \omega\right) \\
& \leq \alpha_{n} \phi\left(x_{0}, \omega\right)+\phi\left(x_{n}, \omega\right) .
\end{aligned}
$$

By virtue of $\sum_{n=0}^{\infty} \alpha_{n}<\infty$ and Lemma 2.10, it follows that the limit of $\left\{\varphi\left(x_{n}, \omega\right)\right\}$ exists. Therefore, $\left\{\varphi\left(x_{n}, \omega\right)\right\}$ is bounded and so $\left\{x_{n}\right\},\left\{u_{n}\right\}$ and $\left\{y_{n}\right\}$ are also bounded. Let $z_{n}=R_{E P(f)} x_{n}$. Then $z_{n} \in E P(f)$ and so, from Lemma 2.7, we have

$$
\phi\left(x_{n}, z_{n}\right)=\phi\left(x_{n}, R_{E P(f)} x_{n}\right) \leq \phi\left(x_{n}, \omega\right)-\phi\left(R_{E P(f)} x_{n}, \omega\right) \leq \phi\left(x_{n}, \omega\right) .
$$

Therefore, $\left\{z_{n}\right\}$ is bounded and so $\varphi\left(x_{0}, z_{n}\right)$ is bounded. Since $\varphi\left(x_{n+1}, z_{n}\right) \leq \alpha_{n} \varphi\left(x_{0}, z_{n}\right)$ $+\varphi\left(x_{n}, z_{n}\right)$, by Lemma 2.7 , one has 


$$
\begin{aligned}
\phi\left(x_{n+1}, z_{n+1}\right) & =\phi\left(x_{n+1}, R_{E P(f)} x_{n+1}\right) \\
& \leq \phi\left(x_{n+1}, z_{n}\right)-\phi\left(R_{E P(f)} x_{n+1}, z_{n}\right) \\
& \leq \phi\left(x_{n+1}, z_{n}\right) \\
& \leq \alpha_{n} \phi\left(x_{0}, z_{n}\right)+\phi\left(x_{n}, z_{n}\right) .
\end{aligned}
$$

Since $\left\{\varphi\left(x_{0}, z_{n}\right)\right\}$ is bounded, there exists $M>0$ such that $\left|\varphi\left(x_{0}, z_{n}\right)\right| \leq M$. By $\sum_{n=0}^{\infty} \alpha_{n}<\infty$, we have

$$
\sum_{n=0}^{\infty} \alpha_{n} \phi\left(x_{0}, z_{n}\right) \leq M \sum_{n=0}^{\infty} \alpha_{n}<\infty,
$$

that is, $\sum_{n=0}^{\infty} \alpha_{n} \phi\left(x_{0}, z_{n}\right)<\infty$ From Lemma 2.10, it follows that $\left\{\varphi\left(x_{n}, z_{n}\right)\right\}$ is a convergent sequence. For any $m \in Z_{+} \backslash\{0\}$, one can get

$$
\phi\left(x_{n+m}, \omega\right) \leq \phi\left(x_{n}, \omega\right)+\sum_{j=0}^{m-1} \alpha_{n+j} \phi\left(x_{0}, \omega\right) .
$$

Then we have

$$
\phi\left(x_{n+m}, z_{n}\right) \leq \phi\left(x_{n}, z_{n}\right)+\sum_{j=0}^{m-1} \alpha_{n+j} \phi\left(x_{0}, z_{n}\right) .
$$

From $z_{n+m}=R_{E P(f)} x_{n+m}$ and Lemma 2.7, it follows that

$$
\phi\left(x_{n+m}, z_{n+m}\right)+\phi\left(z_{n+m}, z_{n}\right) \leq \phi\left(x_{n+m}, z_{n}\right) \leq \phi\left(x_{n}, z_{n}\right)+\sum_{j=0}^{m-1} \alpha_{n+j} \phi\left(x_{0}, z_{n}\right)
$$

and so

$$
\phi\left(z_{n+m}, z_{n}\right) \leq \phi\left(x_{n}, z_{n}\right)-\phi\left(x_{n+m}, z_{n+m}\right)+\sum_{j=0}^{m-1} \alpha_{n+j} \phi\left(x_{0}, z_{n}\right) .
$$

Set $r=\sup \left\{\left\|z_{n}\right\|: n \in Z_{+}\right\}$. Then, from Lemma 2.2 and [19], it follows that there is a strictly increasing, continuous and convex function $h:[0,2 r] \rightarrow R$ such that $h(0)=0$ and

$$
h\left(\left\|z_{n}-z_{n+m} \mid\right\|\right) \leq \phi\left(z_{n+m}, z_{n}\right) \leq \phi\left(x_{n}, z_{n}\right)-\phi\left(x_{n+m}, z_{n+m}\right)+\sum_{j=0}^{m-1} \alpha_{n+j} \phi\left(x_{0}, z_{n}\right) .
$$

Since $\left\{\varphi\left(x_{n}, z_{n}\right)\right\}$ is convergent, $\left\{\varphi\left(x_{0}, z_{n}\right)\right\}$ is bounded and $\sum_{n=0}^{\infty} \alpha_{n}$ is convergent, it follows that, for any $m \in Z_{+}$,

$$
\lim _{n \rightarrow \infty}\left\|z_{n}-z_{n+m}\right\|=0,
$$

which shows that $\left\{z_{n}\right\}$ is a Cauchy sequence. Since $E P(f)$ is closed, there exists $\omega \in$ $E P(f)$ such that $z_{n} \rightarrow \omega$. Therefore, the sequence $\left\{R_{E P(f)} x_{n}\right\}$ converges strongly to the $\omega$ $\in E P(f)$. This completes the proof. $\square$

Theorem 3.2. Let $C$ be a nonempty closed subset of a uniformly convex and uniformly smooth Banach space $E$ such that $J(C)$ is closed and convex. Assume that a 
mapping $f: J(C) \times J(C) \rightarrow R$ satisfies the conditions $(A 1)-(A 4)$. Define a sequence $\left\{x_{n}\right\}$ in $C$ by the following algorithm:

$$
\left\{\begin{array}{l}
x_{0} \in C, \\
u_{n} \in C \text { such that } f\left(J\left(u_{n}\right), J(y)\right)+\frac{1}{r_{n}}\left\langle u_{n}-x_{n}, J(y)-J\left(u_{n}\right)\right\rangle \geq 0, \quad \forall y \in C, \\
x_{n+1}=\alpha_{n} x_{0}+\left(1-\alpha_{n}\right)\left(\beta_{n} x_{n}+\left(1-\beta_{n}\right) u_{n}\right), \quad \forall n \in Z_{+},
\end{array}\right.
$$

where $\left\{\alpha_{n}\right\},\left\{\beta_{n}\right\} \subset[0,1]$ such that

$$
\sum_{n=0}^{\infty} \alpha_{n}<\infty, \quad \liminf _{n \rightarrow \infty} \beta_{n}\left(1-\beta_{n}\right)>0, \quad \liminf _{n \rightarrow \infty} r_{n}>0 .
$$

If $J$ is weakly sequentially continuous, then the sequence $\left\{x_{n}\right\}$ converges weakly to a point $\omega \in E P(f)$, where $\omega=\lim _{n \rightarrow \infty} R_{E P(f)} x_{n}$ and $R_{E P(f)}$ is the sunny generalized nonexpansive retraction from $E$ onto $E P(f)$.

Proof. For the sake of simplicity, let $u_{n}=T_{r_{n}} x_{n}, y_{n}=\beta_{n} x_{n}+\left(1-\beta_{n}\right) u_{n}$ and $z_{n}=R_{E P(f)}$ $x_{n}$. As in the proof of Theorem 3.1, we have $\left\{x_{n}\right\},\left\{u_{n}\right\},\left\{z_{n}\right\},\left\{J\left(x_{n}\right)\right\}$ and $\left\{y_{n}\right\}$ are bounded. Set $r=\sup \left\{\left\|x_{n}\right\|,\left\|z_{n}\right\|: n \in Z_{+}\right\}$. It follows from Lemma 2.2 that there exists a strictly increasing, continuous and convex function $h:[0,2 r] \rightarrow R$ such that $h(0)=0$ and

$$
\left\|\beta_{n} x_{n}+\left(1-\beta_{n}\right) u_{n}\right\|^{2} \leq \beta_{n}\left\|x_{n}\right\|^{2}+\left(1-\beta_{n}\right)\left\|u_{n}\right\|^{2}-\beta_{n}\left(1-\beta_{n}\right) h\left(\left\|x_{n}-u_{n}\right\|\right) .
$$

Since

$$
\begin{aligned}
\phi\left(y_{n}, \omega\right)= & \phi\left(\beta_{n} x_{n}+\left(1-\beta_{n}\right) u_{n}, \omega\right) \\
\leq & \beta_{n}\left\|x_{n}\right\|^{2}+\left(1-\beta_{n}\right)\left\|u_{n}\right\|^{2}-\beta_{n}\left(1-\beta_{n}\right) h\left(\left\|x_{n}-u_{n}\right\|\right) \\
& -2 \beta_{n}\left\langle x_{n}, J(\omega)\right\rangle-2\left(1-\beta_{n}\right)\left\langle u_{n} J(\omega)\right\rangle+\|\omega\|^{2} \\
= & \beta_{n} \phi\left(x_{n}, \omega\right)+\left(1-\beta_{n}\right) \phi\left(u_{n}, \omega\right)-\beta_{n}\left(1-\beta_{n}\right) h\left(\left\|x_{n}-u_{n}\right\|\right) \\
= & \beta_{n} \phi\left(x_{n}, \omega\right)+\left(1-\beta_{n}\right) \phi\left(T_{r_{n}} x_{n}, \omega\right)-\beta_{n}\left(1-\beta_{n}\right) h\left(\left\|x_{n}-u_{n}\right\|\right) \\
\leq & \phi\left(x_{n}, \omega\right)-\beta_{n}\left(1-\beta_{n}\right) h\left(\left\|x_{n}-u_{n}\right\|\right),
\end{aligned}
$$

we have

$$
\begin{aligned}
\phi\left(x_{n+1}, \omega\right)= & \phi\left(\alpha_{n} x_{0}+\left(1-\alpha_{n}\right) y_{n}, \omega\right) \\
& \leq \alpha_{n} \phi\left(x_{0}, \omega\right)+\left(1-\alpha_{n}\right) \phi\left(y_{n}, \omega\right) \\
& \leq \alpha_{n} \phi\left(x_{0}, \omega\right)+\phi\left(y_{n}, \omega\right) \\
& \leq \alpha_{n} \phi\left(x_{0}, \omega\right)+\phi\left(x_{n}, \omega\right)-\beta_{n}\left(1-\beta_{n}\right) h\left(\left\|x_{n}-u_{n}\right\|\right) .
\end{aligned}
$$

Moreover, one has

$$
\beta_{n}\left(1-\beta_{n}\right) h\left(\left\|x_{n}-u_{n}\right\|\right) \leq \phi\left(x_{n}, \omega\right)-\phi\left(x_{n+1}, \omega\right)+\alpha_{n} \phi\left(x_{0}, \omega\right) .
$$

From $\lim \inf _{n \rightarrow \infty} \beta_{n}\left(1-\beta_{n}\right)>0, \sum_{n=0}^{\infty} \alpha_{n}<\infty$ and the limit existence of $\left\{\varphi\left(x_{n}, \omega\right)\right\}$, we have

$$
\lim _{n \rightarrow \infty} h\left(\left\|x_{n}-u_{n}\right\|\right)=0 .
$$

By the property of $h$, we get

$$
\lim _{n \rightarrow \infty} \mid\left\|x_{n}-u_{n}\right\|=0 .
$$


Since $J$ is uniformly norm-to-norm continuous on the bounded subset of $E$, we obtain

$$
\lim _{n \rightarrow \infty}\left\|J\left(x_{n}\right)-J\left(u_{n}\right)\right\|=0 .
$$

Since $\left\{J\left(x_{n}\right)\right\}$ is bounded, we have that $J\left(x_{n}\right) \rightarrow p^{*}$ (here we may take a subnet $\left\{x_{n_{k}}\right\}$ of $\left\{x_{n}\right\}$ if necessary). Then $J\left(u_{n}\right) \rightarrow p^{*}$. From $\lim \inf _{n \rightarrow \infty} r_{n}>0$, it follows that $\lim _{n \rightarrow \infty} \frac{\left\|x_{n}-u_{n}\right\|}{r_{n}}=0$. Note that

$$
f\left(J\left(u_{n}\right), J(y)\right)+\frac{1}{r_{n}}\left\langle u_{n}-x_{n}, J(y)-J\left(u_{n}\right)\right\rangle \geq 0 .
$$

By $(A 2)$, we obtain

$$
f\left(J(y), J\left(u_{n}\right)\right) \leq-f\left(J\left(u_{n}\right), J(y)\right) \leq \frac{1}{r_{n}}\left\langle u_{n}-x_{n}, J(y)-J\left(u_{n}\right)\right\rangle .
$$

Therefore, it follows that $f\left(J(y), p^{*}\right) \leq 0$. Let $\gamma_{t}^{*}=t J(\gamma)+(1-t) p^{*}$ for any $t \in(0,1)$. Then $\gamma_{t}^{*} \in J(C)$. Since

$$
0=f\left(y_{t}^{*}, y_{t}^{*}\right) \leq t f\left(y_{t}^{*}, J(\gamma)\right)+(1-t) f\left(y_{t}^{*}, p^{*}\right) \leq t f\left(y_{t}^{*}, J(\gamma)\right) ，
$$

we get $f\left(\gamma_{t}^{*}, J(\gamma)\right) \geq 0$. By $(A 3)$, one has $f\left(p^{*}, J(y)\right) \geq 0$.Therefore, $p^{*} \in J(E P(f))$.

Let $z_{n}=R_{E P(f)} x_{n}$. From Theorem 3.1, one can get that $z_{n} \rightarrow \omega$ and so

$$
\left\langle x_{n}-z_{n}, p^{*}-J\left(z_{n}\right)\right\rangle \leq 0 .
$$

Since $J$ is weakly sequentially continuous, we have

$$
\left\langle J^{-1}\left(p^{*}\right)-J^{-1}(J(\omega)), J(\omega)-p^{*}\right\rangle \geq 0 .
$$

By the monotonicity of $J^{1}$,

$$
\left\langle J^{-1}\left(p^{*}\right)-J^{-1}(J(\omega)), J(\omega)-p^{*}\right\rangle \leq 0 .
$$

Thus, from both (3.1) and (3.2), it follows that

$$
\left\langle J^{-1}\left(p^{*}\right)-J^{-1}(J(\omega)), J(\omega)-J\left(J^{-1}\left(p^{*}\right)\right)\right\rangle=0,
$$

this together with the strictly monotonicity of $J$ yields that $J^{-1}\left(p^{*}\right)=\omega$. Therefore, the sequence $\left\{x_{n}\right\}$ converges weakly to the point $\omega \in E P(f)$, where $\omega=\lim _{n \rightarrow \infty} R_{E P(f)} x_{n}$. This completes the proof. $\square$

\section{Numerical test}

In this section, we give an example of numerical test to illustrate the algorithms given in Theorems 3.1 and 3.2.

Example 4.1. Let $E=R, C=[-1000,1000]$ and define $f(x, y):=-5 x^{2}+x y+4 y^{2}$. Find $\bar{x} \in C$ such that

$$
f(\bar{x}, y) \geq 0, \quad \forall y \in C .
$$

First, we verify that $f$ satisfies the conditions (A1)-(A4) as follows:

(A1) $f(x, x)=-5 x^{2}+x^{2}+4 x^{2}=0$ for all $x \in[-1000,1000]$;

(A2) $f(x, y)+f(y, x)=-(x-y)^{2} \leq 0$ for all $x, y \in[-1000,1000]$; 
(A3) For all $x, y, z \in[-1000,1000]$,

$$
\begin{aligned}
\limsup _{t \rightarrow 0^{+}} f(x+t(z-x), y) & =\limsup _{t \rightarrow 0^{+}}-5((1-t) x+t z)^{2}+(1-t) x y+t z y+4 y^{2} \\
& =-5 x^{2}+x y+4 y^{2} \\
& \leq f(x, y) .
\end{aligned}
$$

(A4) For all $x \in[-1000,1000], F(y)=f(x, y)=-5 x^{2}+x y+4 y^{2}$ is convex and lower semicontinuous.

From Lemma 2.4, $T_{r}$ is single-valued. Now, we deduce a formula for $T_{r}(x)$. For any $y$ $\in C, r>0$,

$$
f(z, y)+\frac{1}{r}\langle z-x, y-z\rangle \geq 0 \Leftrightarrow 4 r y^{2}+((r+1) z-x) y+x z-(5 r+1) z^{2} \geq 0 .
$$

Set $G(y)=4 r y^{2}+((r+1) z-x) y+x z-(5 r+1) z^{2}$. Then $G(y)$ is a quadratic function of $y$ with coefficients $a=4 r, b=(r+1) z-x$ and $c=x z-(5 r+1) z^{2}$. So its discriminant $\Delta=b^{2}-4 a c$ is

$$
\begin{aligned}
\Delta & =[(r+1) z-x]^{2}-16 r\left(x z-(5 r+1) z^{2}\right) \\
& =(r+1)^{2} z^{2}-2(r+1) x z+x^{2}-16 r x z+\left(80 r^{2}+16 r\right) z^{2} \\
& =[(9 r+1) z-x]^{2} .
\end{aligned}
$$

Since $G(y) \geq 0$ for all $y \in C$, this is true if and only if $\Delta \leq 0$. That is, $[(9 r+1) z-x]^{2} \leq$ 0 . Therefore, $z=\frac{x}{9 r+1}$, which yields that $T_{r}(x)=\frac{x}{9 r+1}$. Let $r_{n}=\frac{n}{n+1}, \beta_{n}=\frac{n}{3 n+1}$ and $\alpha_{n}=\frac{1}{(3 n+1)^{2}}$. It is easy to check that

$$
\sum_{n=0}^{\infty} \alpha_{n}<+\infty, \quad \liminf _{n \rightarrow \infty} \beta_{n}\left(1-\beta_{n}\right)=\frac{2}{9}>0, \quad \liminf _{n \rightarrow \infty} r_{n}=1 .
$$

Thus, from Lemma 2.4, it follows that $E P(f)=\{0\}$. Therefore, all the assumptions in Theorems 3.1 and 3.2 are satisfied. Setting $x_{0}=1$ and using the algorithm in Theorem 3.1, we obtain the following sequences:

$$
\left\{\begin{array}{l}
x_{0}=1 \\
u_{n}=T_{r_{n}}\left(x_{n}\right)=\frac{n+1}{10 n+1} x_{n} \\
x_{n+1}=\frac{1}{(3 n+1)^{2}} x_{0}+\frac{108 n^{4}+108 n^{3}+33 n^{2}+6 n}{270 n^{4}+297 n^{3}+117 n^{2}+19 n+1} x_{n}
\end{array}\right.
$$

Therefore, by Theorem 3.1, the sequence $\left\{P_{E P(f)} x_{n}\right\}$ must converge strongly to a solution of the problem (4.1). In fact, $P_{E P(f)} x_{n}=0$ for all $n \in Z_{+}$. Also, according to Theorem 3.2, the sequence $\left\{x_{n}\right\}$ converges weakly to a solution of the problem (4.1). For a number $\varepsilon=10^{-3}$, if we use MATLAB, then we generate a sequence $\left\{x_{n}\right\}$ as follows:

Selected values of $\left\{u_{n}\right\}$ and $\left\{x_{n}\right\}$ computed by computer programs are listed below Tables 1 and 2, respectively. The convergent process of the sequence $\left\{x_{n}\right\}$ is described in Figure 1.

Table 1 Selected values of $\left\{u_{n}\right\}$

\begin{tabular}{cccccc}
\hline$u_{n}$ & $u_{n}$ & $u_{n}$ & $u_{n}$ & $u_{n}$ & $u_{n}$ \\
\hline 0.1818 & 0.0607 & 0.0026 & 0.0012 & 0.0007 & 0.0003 \\
0.0002 & 0.0001 & 0.0001 & 0.0001 & 0.0000 & 0.0000 \\
\hline
\end{tabular}


Table 2 Selected values of $\left\{x_{n}\right\}$

\begin{tabular}{cccccc}
\hline $\boldsymbol{x}_{\boldsymbol{n}}$ & $\boldsymbol{x}_{\boldsymbol{n}}$ & $\boldsymbol{x}_{\boldsymbol{n}}$ & $\boldsymbol{x}_{\boldsymbol{n}}$ & $\boldsymbol{x}_{\boldsymbol{n}}$ & $\boldsymbol{x}_{\boldsymbol{n}}$ \\
\hline 0.4247 & 0.0204 & 0.0100 & 0.0059 & 0.0028 & 0.0021 \\
0.0016 & 0.0013 & 0.0010 & 0.0008 & 0.0007 & 0.0006 \\
0.0005 & 0.0004 & 0.0003 & 0.0003 & 0.0002 & 0.0002 \\
0.0002 & 0.0002 & 0.0002 & 0.0001 & 0.0001 & 0.0001 \\
0.0001 & 0.0001 & 0.0001 & 0.0001 & 0.0001 & 0.0001 \\
0.0001 & 0.0001 & 0.0001 & 0.0000 & 0.0000 & 0.0000 \\
\hline
\end{tabular}

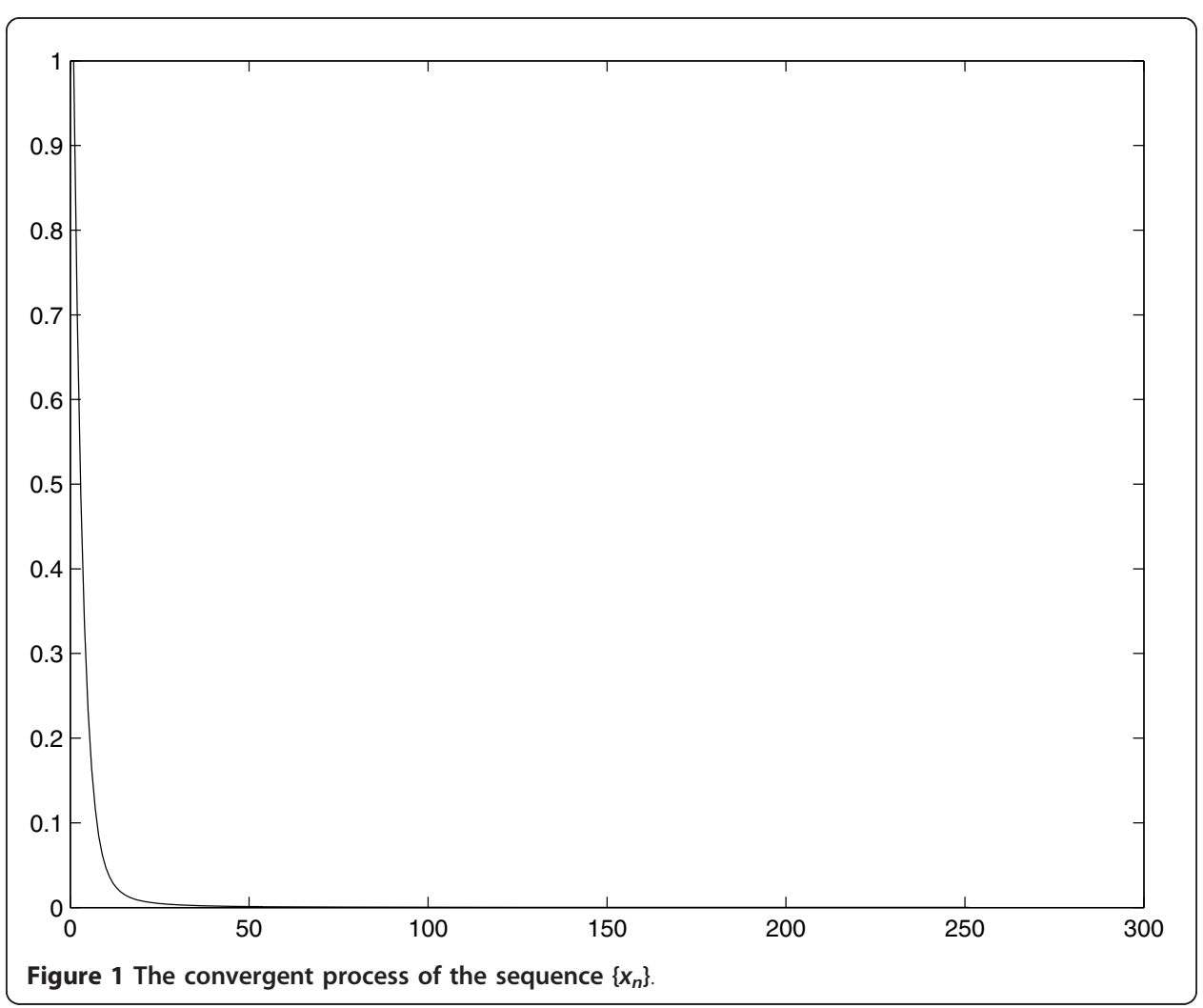

From Table 1, we can see that the sequence $\left\{u_{n}\right\}$ converges to 0 . Moreover, $F\left(T_{r}\right)=$ $E P(f)=\{0\}$. Table 2 shows that the iterative sequence $\left\{x_{n}\right\}$ converges to 0 , which is indeed a solution of the problem (4.1). Moreover, $\lim _{n \rightarrow \infty} P_{E P(f)} x_{n}=0$.

\section{Acknowledgements}

The authors would like to thank three anonymous referees for their invaluable comments and suggestions, which led to an improved presentation of the results. This work was supported by the Natural Science Foundation of China (71171150, 70771080), the Korea Research Foundation Grant funded by the Korean Government (KRF-2008-313C00050), the Academic Award for Excellent Ph.D. Candidates Funded by Wuhan University and the Fundamental Research Fund for the Central Universities (201120102020004).

\section{Author details}

${ }^{1}$ School of Mathematics and Statistics, Wuhan University, Wuhan, Hubei 430072, China ${ }^{2}$ Department of Mathematics Education and the RINS, Gyeongsang National University, Chinju 660-701, Republic of Korea

\section{Authors' contributions}

J-WC, YJC and ZW carried out the studies on nonlinear analysis and applications, wrote this article together and participated in its design of this paper. All authors read and approved the final manuscript. 


\section{References}

1. Blum, E, Oettli, W: From optimization and variational inequalities to equilibrium problems. Mathe Stud. 63, 123-145 (1994)

2. Ceng, LC, Mastronei, G, Yao, JC: Hybrid proximal-point methods for common solutions of equilibrium problems and zeros of maximal monotone operators. J Optim Theory Appl. 142, 431-449 (2009). doi:10.1007/s10957-009-9538-Z

3. Cho, YJ, Argyros, IK, Petrot, N: Approximation methods for common solutions of generalized equilibrium, systems of nonlinear variational inequalities and fixed point problems. Comput Math Appl. 50, 2292-2301 (2010)

4. Cho, YJ, Qin, X, Kang, J: Convergence theorems based on hybrid methods for generalized equilibrium problems and fixed point problems. Nonlinear Anal (TMA). 71, 4203-4214 (2009). doi:10.1016/j.na.2009.02.106

5. Combettes, PL, Hirstoaga, SA: Equilibrium programming in Hilbert spaces. J Nonlinear Convex Anal. 6, 117-136 (2005)

6. Takahashi, S, Takahashi, W: Viscosity approximation methods for equilibrium problems and fixed point problems in Hilbert space. J Math Anal Appl. 331, 506-515 (2007). doi:10.1016/j.jmaa.2006.08.036

7. Takahashi, S, Takahashi, W: Strong convergence theorems for a generalized equilibrium problem and a nonexpansive mapping in Hilbert space. Nonlinear Anal (TMA). 69, 1025-1033 (2008). doi:10.1016/j.na.2008.02.042

8. Yao, Y, Cho, YJ, Chen, R: An iterative algorithm for solving fixed point problems, variational inequality problems and mixed equilibrium problems. Nonlinear Anal (TMA). 71, 3363-3373 (2009). doi:10.1016/j.na.2009.01.236

9. Takahashi, W, Zembayashi, K: Strong and weak convergence theorems for equilibrium problems and relatively nonexpansive mappings in Banach spaces. Nonlinear Anal(TMA). 70, 45-57 (2009). doi:10.1016/j.na.2007.11.031

10. Ibaraki, T, Takahashi, W: A new projection and convergence theorems for the projections in Banach spaces. J Approx Theory. 149, 1-14 (2007). doi:10.1016/j.jat.2007.04.003

11. Honda, T, Takahashi, W, Yao, JC: Nonexpansive retractions onto closed convex cones in Banach spaces. Taiwanese $J$ Math. 14, 1023-1046 (2010)

12. Kohsaka, F, Takahashi, W: Generalized nonexpansive retractions and a proximal-type algorithm in Banach spaces. J Nonlinear Convex Anal. 8, 197-209 (2007)

13. Takahashi, W, Takeuchi, Y, Kubota, R: Strong convergence theorems by hybrid methods for families of nonexpansive mappings in Hilbert spaces. J Math Anal Appl. 341, 276-286 (2008). doi:10.1016/j.jmaa.2007.09.062

14. Takahashi, W, Zembayashi, K: A Strong convergence theorem for the equilibrium problem with a bifunction defined on the dual space of a Banach space. Proceeding of the 8th International Conference on Fixed Point Theory and its Applications. pp. 197-209.Yokohama Publish:Yokohama (2008)

15. Alber, Y: Generalized projection operators in Banach spaces: properties and applications. In Proceedings of the Israel Seminar Ariel, vol. 1, pp. 1-21.Israel Funct Differ Equat (1994)

16. Alber, Y: Metric and generalized projection operators in Banach spaces: properties and applications. In: Kartsatos AG (ed.) Theory and Applications of Nonlinear Operators of Monotonic and Accretive Type. pp. 15-50. Dekker:New York (1996)

17. Takahashi, W: Nonlinear Functional Analysis-Fixed Point Theory and Its Applications. Yokohama Publishers. (2000)

18. Xu, HK: Inequalities in Banach spaces with applications. Nonlinear Anal (TMA). 16, 1127-1138 (1991). doi:10.1016/0362 546X(91)90200-K

19. Kamimura, S, Takahashi, W: Strong convergence of a proximal-type algorithm in a Banach space. SIAM J Optim. 13, 938-945 (2003)

20. Deimling, K: Nonlinear Functional Analysis. Springer, Berlin (1985)

21. Tan, KK, Xu, HK: Approximating fixed points of nonexpansive mappings by the Ishikawa iteration process. J Math Anal Appl. 178, 301-308 (1993). doi:10.1006/jmaa.1993.1309

doi:10.1186/1687-1812-2011-91

Cite this article as: Chen et al: Shrinking projection algorithms for equilibrium problems with a bifunction defined on the dual space of a Banach space. Fixed Point Theory and Applications 2011 2011:91.

\section{Submit your manuscript to a SpringerOpen ${ }^{\circ}$ journal and benefit from:}

- Convenient online submission

Rigorous peer review

- Immediate publication on acceptance

- Open access: articles freely available online

- High visibility within the field

- Retaining the copyright to your article

Submit your next manuscript at $>$ springeropen.com 